\title{
ASPECTS OF FUTURE TRANSPORT: LONG TERM MAGLEV STRATEGIES INSTEAD OF CONVENTIONAL RAIL CONCEPTS?
}

\author{
J. Kluehspies \\ The International Maglev Board \\ (Munich, Germany)
}

The idea of considering Maglev systems challenges established ways of thinking on how to deal with an increasing transport demand. Today, the railway industry seems focused on traditional business models that profit from friction, wear and tear of established conventional transport systems. It is Maglev Systems that have begun to challenge those traditional business concepts. Maglev is a fundamentally different concept of transport - which might explain the reluctance, even ignorance, which Maglev systems continue to face.

The less competition in the market, the more attractive it appears in the shortterm for manufacturers to postpone a technological innovation like Maglev and to secure current sources of income through long-term maintenance contracts (delivery, spare parts) that are linked to conventional wheel/rail contracts. Such an orientation on the commercially lucrative (rather than on the system-technologically superior) can strongly handicap, delay or even stop transportation technological innovations.

As the lifetime of high-speed rail/wheel infrastructures comes to an end, the technology question will arise again. Based on the operation experiences with highspeed-trains, the technology question is likely to arise significantly earlier than generally expected. The question then will be whether in restoring or maintaining Trans-European high-speed routes (Eastern Europe, UK) the conventional wheel/rail technology continues to be used or whether such corridors should better be based on high-speed Maglev technology.

Worldwide, there are currently only very few corridors left, for which interurban high-speed Maglev transport is potentially qualified or might appear meaningful. But for such new corridor routes, for example such as:

- the Brazilian Rio de Janeiro - Sao Paulo corridor;

- the corridor Hamburg - Berlin - Warsaw/Baltic States - St. Petersburg - Moscow;

- the Pan-European corridor IV (Berlin - Prague - Vienna - Budapest);

- the Washington - Baltimore corridor (USA) or even;

- the UK corridor (London - Liverpool; Glasgow, Edinburgh),

a detailed, fair technology comparison and examination should be made with regard to high-speed Maglev.

Japan already leapfrogs to high speed Maglev systems. Russia strives for Cargo Maglev strategies. China and Korea boost the implementation of Urban Maglev technologies. Transrapid Maglev technology is being further developed by 
Chinese Universities. And Germany has begun to build elevators based on Maglev technology.....

Sooner or later, a paradigm shift in transport in favour of Maglev seems likely.

\section{Information about author:}

Johannes Kluehspies, e-mail: jok.geo@t-online.de

(C) Johannes Kluehspies 